\title{
Desarrollo comunitario, economía solidaria, empoderamiento y participación. Un camino para la lucha social
}

\section{Carlos Montaño*}

Resumen. En general, el debate en las Ciencias Sociales ha sido trastocado por el positivismo y el posmodernismo. El debate sobre el desarrollo, que giraba en torno al desarrollo desigual, las relaciones entre centro y periferia o la dependencia con su eventual salida hacia el socialismo, ha sido suplido por el (neo)desarrollismo, que se engloba en la fórmula de menos Estado y más sociedad civil y mercado, lo cual da lugar a términos como tercer sector, emprendedurismo, responsabilidad social, sustentabilidad, entre otros. Asimismo, la discusión sobre el poder político, que se había concebido como una relación social desigual o una correlación de fuerzas, ahora se expresa como un poder subjetivo, autopoder o poder sobre sí, en el plano personal, interno y psicológico, independiente de las relaciones sociales. Para superar esas concepciones limitadas se requiere una visión de totalidad, un pensamiento crítico y una perspectiva de transformación social. Es preciso desideologizar el lenguaje del análisis social y desmontar el proyecto de reestructuración del capital: comprender el significado real de los términos del debate y reconocer los intereses que expresan y las contradicciones y luchas que encubren. Para ejercer la crítica social radical hay que regresar a las categorías fundacionales del capitalismo, retomar la perspectiva de la transformación social y superar las visiones fragmentadas de la realidad. Además, asumirse como un «intelectual orgánico», comprometido con el movimiento de la historia, los movimientos sociales, las clases trabajadoras organizadas, sin por ello confundir la actividad científica o profesional con la militancia partidaria.

Palabras clave: desarrollo, poder, conocimiento, economía solidaria, transformación.

* Profesor asociado e investigador de la Universidade Federal do Rio de Janeiro (UFRJ), Río de Janeiro, Brasil.

Traducción del portugués por Humberto Márquez Covarrubias. 


\section{Community development, solidarity economy, empowerment and participation. A way ahead for the social struggle}

Abstract. In general terms. the debate within the social sciences has been subverted by positivism and post-modernism. The debate on development, which revolves around unequal development, the relationships between the center and the periphery or dependency with its eventual arrival at socialism, has been substituted by (neo)developmentalism, which encompasses the formula of less State and more civil society and market, which gives rise to terms such as third sector, entrepreneurship, social responsibility, and sustainability, among others. Similarly, the discussion around political power, which has been conceived as an unequal social relation or a correlation of forces, is now expressed as a subjective power, self-power or power above all, at the personal level, internal and psychological, independent of social relations. To overcome these limited conceptions we require a vision of the totality, critical thinking and a perspective of social transformation. It must de-ideologize the language of social analysis and dismantle the restructuring project of capital: to understand the true meaning of the terms of debate and recognize the interests that they express and the contradictions and struggles that they disguise. In order to employ the critical-radical-social approach, one must look back at the foundational categories of capitalism, recapturing the perspective of social transformations and overcoming the fragmented visions of reality. Also, one must approach it as an «organic intellectual», appreciating the march of history, social movements, organized working classes, without confusing scientific or professional work with partisan militancy.

Keywords: development, power, knowledge, solidarity economy, transformation. 


\section{Conocimiento y lenguaje: la función de desvelar u ocultar lo real}

Existe, como requisito para perpetuar la hegemonía, entendida en su sentido gramsciano, la necesidad de desarrollar una dirección social más allá de la mera coerción (pero siempre presente en una sociedad de clases). En el contexto actual de crisis sistémica, la (fracción de) clase hegemónica debe insertar su proyecto de reestructuración sistémica (neoliberal) con la menor resistencia y oposición posibles; este proyecto debe tener un mínimo razonable de legitimidad y aceptación social.

Pero, ¿cómo generar la aceptación de un proyecto claramente regresivo en términos de derechos y logros laborales, políticos y sociales? Este tema constituyó un desafío significativo para el logro del proyecto hegemónico para la reestructuración del capital, bajo el mando neoliberal.

La respuesta, además de la represión obvia, es tanto la expansión de una racionalidad hiperdesarticuladora como fragmentadora de la totalidad social, ya sea por la razón formal-abstracta: positivismo, neopositivismo, sistemismo, etcétera, o por la llamada razón «posmoderna», como la imposición de un «lenguaje» que ideológicamente ${ }^{1}$ conduce a una visión fetichizada y reificada de la realidad, ocultando el verdadero significado de las reformas y mostrándolas como «voluntad popular». Un lenguaje, por lo tanto, que oculta su carácter de clase, que «importa» los términos de las viejas banderas progresistas (democracia, justicia, poder social, popular, solidario, participativo, etcétera), pero las reconfigura con otros contenidos, ahora funcionales para los intereses conservadores o restauradores de

${ }^{1}$ Para el sentido de ideología marx-engelsiano como «falsa conciencia», véase Marx y Engels (1977). 


\section{CARLOS MONTAÑo}

la gran burguesía, pero en este caso ocultos en los discursos de sectores de la izquierda. Mejor, veamos.

\section{Las visiones intelectuales y fragmentadas de la realidad:} racionalidades formal-abstractas y «posmodernas»

En la producción y difusión del conocimiento sobre lo real, el intelectual tiene un papel destacado. Veamos cómo, al producir conocimiento, el intelectual, y entre ellos el «científico social», ha tenido una visión fragmentada de lo real y, por lo tanto, ha tendido a desarrollar y reproducir, tendencialmente, un conocimiento fragmentado.

Por lo tanto, lo intelectual («orgánico» o no) nace, en el presente, imbuido de una tendencia cultural positivista (como la expresión principal de la razón formal-abstracta), que tiene como objetivo segmentar la realidad en las esferas sociales («objetos específicos»), constituyendo, a partir de esta segmentación, "campos del conocimiento» y «disciplinas sociales» específicas. Esto es lo que Lukács llama las «Ciencias Sociales Particulares» (en este sentido, véase Lukács, 1992; Coutinho, 1994).

Por lo tanto, la hegemonía del sistema capitalista consolidado se mantiene no sólo con coerción, sino que necesita un cierto grado de aceptación general (véase Marx y Engels, 1977), de consenso (véase Gramsci, 2000). De esta manera, la ideología, los valores y las normas burguesas deben ser incorporados por la población como una «cultura oficial», que obliga a la clase hegemónica a dos dispositivos: la «naturalización» y el ocultamiento o incluso la fetichización de los mismos. Los valores y normas «naturalizados» $\mathrm{y}$ «fetichizados» son luego deshistorizados; en este sentido, son vistos como naturales e incomprensibles o indescifrables, por lo tanto, inmutables. La 
forma de hacerlo es desarrollar un tipo de racionalidad que al mismo tiempo segmente y manipule lo real.

Si el positivismo era racionalidad hegemónica, dada su funcionalidad con el tipo de conocimiento compatible con los intereses del capital, hoy el pensamiento posmoderno se presenta como una nueva racionalidad hegemónica, que no sólo fragmenta lo real en esferas aisladas, sino también pulveriza la realidad, eliminando su objetividad, transformando la realidad en «las realidades» experimentadas, sentidas (véase Jameson, 1996; Harvey, 1993).

El intelectual (el científico social en particular) para escapar de esta trampa, esta «jaula de hierro» positivista y/o posmoderna, debe incorporar y desarrollar: 1. Una visión de totalidad. 2. Un pensamiento crítico. 3. Una perspectiva de transformación social.

\section{La función ideológica del nuevo lenguaje: \\ el lenguaje de izquierda y el proyecto correcto}

El conocimiento producido (fragmentado o no, funcional para la reproducción del orden o su transformación), para ser apropiado por otros, se difunde a través de un tipo de lenguaje, que aún puede ayudar tanto a la comprensión fiel de lo real como a su mistificación. En este sentido, el lenguaje tiene un papel destacado, y en el contexto actual, para legitimar las transformaciones antipopulares, los sectores hegemónicos desarrollan un nuevo lenguaje.

En efecto, la (nueva) nomenclatura, el (nuevo) lenguaje, debe camuflar el verdadero contenido regresivo y antipopular de estas reformas y mostrarlas como ajustes, mejoras, modernizaciones, como respuestas a las necesidades 


\section{CARLOS MONTAÑo}

populares. Como afirman los editores argentinos de Petras, el hilo conductor de los pensamientos de este autor en sus conferencias en ese país muestra «la convicción de que la hegemonía cultural lograda por el imperialismo entre los intelectuales [y la población en general], incluidos los de la izquierda, ha impuesto un lenguaje adrede eufemístico que oscurece intencionalmente la comprensión del mundo real» (Petras, 2000:8). O, en los propios términos de Petras, «el problema básico es que parte de la hegemonía recientemente conquistada por el capital se encuentra en el uso del lenguaje y los términos analíticos que oscurecen las relaciones reales, los procesos de explotación social y la reconcentración del poder social» (Petras, 1999:55).

Por lo tanto, este lenguaje debe ir más allá de la derecha y los grupos dominantes, e incluso penetrar en la izquierda y los sectores «populares», porque, en términos de Petras, «la regresión de los derechos sociales y laborales (...) no podría ocurrir usando el lenguaje de interés propio de los capitalistas»; de esta manera, continúa, «se elaboró un nuevo lenguaje, que en algunos casos tomó prestados términos esenciales de la izquierda»; el objetivo, dice nuestro autor, en esta «tarea ideológica de mistificación científica», era «crear un lenguaje y conceptos que parecieran ser técnicos o apolíticos, que parecieran estar divorciados de los intereses de clase que servían» (Petras, 1999:62). Por lo tanto, para este autor, «las ONG usan [y difunden] el lenguaje de la izquierda: ‘poder popular`, ‘delegación de poderes», igualdad de género», ‘desarrollo de base`, etcétera. El problema es que este lenguaje está vinculado a la estructura de colaboración con donantes y agencias gubernamentales que subordinan la actividad práctica a las políticas de no confrontación» (Petras, 1999:48). Estos términos, generalmente provenientes del pensamiento progresista, de las luchas históricas de la izquierda, se reconceptualizan de acuerdo con los intereses hegemónicos 
del gran capital, para que este nuevo contenido conservador o regresivo sea mejor aceptado entre los sectores subalternos, oprimidos y explotados.

Por otro lado, en muchos casos, con las mejores intenciones de superar los prejuicios y las formas de discriminación social, los términos que se consideran «prejuiciosos» son reemplazados por otros que son «políticamente correctos». Así: «anciano» por «adulto mayor», «parapléjico» por «persona con necesidades especiales», «edad adulta» por «mayoría de edad», «favela» por «comunidad». Sin cuestionar el hecho real de que las palabras conllevan los prejuicios y la discriminación que las crean, el cambio en los términos hace poco por cambiar el problema subyacente, pero, por el contrario, termina por ocultarlas; persisten la discriminación y los prejuicios, pero ahora disfrazados, camuflados en la nueva palabra considerada «políticamente correcta».

Entonces, la clase dominante, para ocultar y legitimar sus proyectos, usa palabras y términos de la izquierda, las banderas progresistas históricas: «democratización», «popular», «solidario», «empoderamiento», «igualdad», «participativo», pero vaciando y refuncionalizando su contenido, así como los términos «políticamente correctos»; tanto para el uso diario de la intelectualidad como para la militancia de una «izquierda posibilista».

Por lo tanto, se desarrolla en estos intelectuales y activistas, parafraseando a Lukács en The Theory of Romance, un lenguaje de izquierda que oculta un proyecto de derecha. ${ }^{2}$

Hoy, la izquierda y la derecha hablan en los mismos términos. Este es el gran papel ideológico y desconcertante de la nueva nomenclatura: convertir el proyecto que responde a los intereses de la fracción de la clase

${ }^{2}$ Lukács señala la coexistencia de «una ética de la izquierda y una epistemología de la derecha» (1963:18). 


\section{CARLOS MONTAÑo}

dominante en un proyecto aceptado por todos, cantando el «canto de las sirenas».

La función ideológica de la «palabra» aquí expresa su lado opresivo: quien tiene conocimiento, quien controla el lenguaje, tiene un camino abierto para dominar al otro. Aquí hay unos ejemplos:

Vivimos, por lo tanto, en una era donde todo tiende a ser fetichizado, ideologizado, reificado, mistificado, naturalizado, fragmentado, ocultando así el verdadero significado de las cosas. Las palabras de hoy son más útiles para esconder que para revelar. Estas palabras son los versos del «canto de las sirenas».

Combatir esta trampa del nuevo lenguaje requiere que los intelectuales (y los militantes) comprometidos con los «sectores subordinados» sean astutos en la comprensión del significado real de los términos a la luz de su inserción en la totalidad social, explicando a sus promotores los intereses que expresan y los que se esconden, las contradicciones y luchas que esconden; deben pensar los términos a la luz de la crítica radical.

\section{La izquierda, el intelectual y las luchas por la hegemonía: el proceso} de cooptación y pacificación del intelectual y el militante de «izquierda»

La organización y las luchas de clase, y las elecciones políticas sobre tácticas y estrategias, siempre están vinculadas al grado de conciencia de clase de los activistas políticos y, por lo tanto, al papel del intelectual. La forma de conocer la realidad produce formas de conciencia de la realidad, que están relacionadas con la organización y las luchas. Así, también en este proceso de luchas, el intelectual tiene un papel destacado en la producción y difusión del conocimiento, orientado hacia la crítica o la mistificación de la realidad. 
Por lo tanto, atacar o cooptar al intelectual (incluido el izquierdista) es una tarea fundamental para los sectores hegemónicos.

Veamos, entonces, cuándo y cómo este intelectual de «izquierda» tiende a ser atacado/cooptado por grupos hegemónicos.

Siguiendo a James Petras (2000), cuando se trata del «imperialismo y los intelectuales», el sorprendente éxito ideo-político del gran capital transnacional y el imperialismo ha sucedido debido a la capacidad de capturar la adhesión de varios intelectuales latinoamericanos. Esto ha sido posible, según el autor, por haber logrado a) disociar al intelectual de las luchas populares, y b) reemplazar el papel del intelectual (comprometido) por el de consultor (neutral).

El autor identifica tres momentos en que el imperialismo estadounidense ha tratado de cooptar a los intelectuales latinoamericanos:

1. En el periodo de 1948 a 1958, después de la Segunda Guerra Mundial, y durante la primera fase de la Guerra Fría, para enfriar la influencia del «ejemplo soviético», particularmente con el «macartismo». El intelectual fue cooptado induciendo miedo, represión, persecución política.

2. En el periodo de 1959 a 1979, después de la Revolución cubana, ahora con el objetivo fundamental de revertir la tendencia a generalizar la revolución en América Latina. El «desarrollismo» en el continente se fomenta a través de la Alianza para el Progreso (Alpro); se promueve un proceso de reforma para enfriar la tendencia a la revolución; el gobierno de Washington se acerca a la «nueva izquierda» o «izquierda democrática» con el objetivo de disminuir la influencia de la «izquierda comunista» o la «izquierda radical» (como el «mayo francés» de 1968). Después de eso, se promueven dictaduras militares en casi todo el subcontinente (Paraguay: de 1954 al 3 de febrero de 


\section{CARLOS MONTAÑo}

1989; Guatemala: de 1960 a 1986; El Salvador: de 1962 a 1975; Brasil: del 31 de marzo de 1964 a 1985; Honduras: de 1963 a 1980; Panamá: de 1968 a 1989; Bolivia: agosto de 1971 a 1978; Chile: del 11 de septiembre de 1973 al 11 de marzo de 1990; Uruguay: del 27 de junio de 1973 a 1985; Perú: de 1975 a 1980; Argentina: del 24 de marzo de 1976 al 10 de diciembre de 1983).

3. En el periodo comprendido entre mediados de la década de 1980 hasta el presente, con la crisis del llamado "socialismo real», con el regreso de los intelectuales exiliados en Europa, en un contexto de crisis capitalista, se alientan las fundaciones y la reconexión académica de estos intelectuales; las consignas se convierten en «democratización» (sin embargo, vacía de su contenido político-instrumental) y «cambio pacífico» (Petras, 2000:89-92).

Tal sustitución conceptual/categórica, en primer lugar, implica un cambio heurístico significativo; es decir, no se trata sólo de «lenguaje», «términos», sino del arsenal heurístico, los instrumentos que tenemos y usamos para comprender la realidad. ${ }^{3}$ En segundo lugar, esta sustitución proyecta un cambio significativo en los objetivos y propósitos militantes: renunciar al proyecto socialista, objetivos anticapitalistas o incluso laborales, y reorientarse al campo de las ideologías subjetivistas, a las acciones afirmativas, a las necesidades inmediatas (y desarticuladas).

Los intelectuales y los militantes cooptados por esta seductora propuesta (que articula el «lenguaje de la izquierda» con la inserción y el financiamiento de fundaciones y ONG como el camino hacia la democratización), como veremos a continuación, están encantados con la ideología

\footnotetext{
${ }^{3}$ Es significativamente diferente pensar en la realidad a través de categorías como «explotación», «contradicción», «luchas de clases», «imperialismo», etcétera, que usar los conceptos de «exclusión social», «paradoja», «armonía» o «asociación», «acción social», «globalización», etcétera.
} 
del "tercer sector» e incorporan sus "nuevos proyectos»: el «empoderamiento», la «responsabilidad social corporativa», la «inclusión social» a través de la cultura y la educación, la «estimulación del capital social», la «economía solidaria», el «fortalecimiento de la sociedad civil organizada», la expansión de las acciones del «tercer sector» u ONG, la «humanización del capital», el «capitalismo verde» y la «producción autosuficiente». Todo dentro de una racionalidad positivista y liberal e incluso posmoderna, pero funcional a los intereses del proyecto neoliberal, de responsabilidad de los sujetos. Estos, por lo tanto, no son proyectos corporativos, sino que se insertan claramente (o se vuelven funcionales) como subproyectos en los valores e intereses del proyecto neoliberal.

Si sus contenidos son claramente funcionales a los intereses hegemónicos de la burguesía, sus difusores y promotores son actores de los sectores populares y/o de la «izquierda posibilista»; es decir, si estos subproyectos están sujetos a la alta burguesía, por responder directamente a sus intereses de clase, tienen como difusores, operadores y ejecutores a esta intelectualidad y militancia de la «izquierda posibilista».

Enfrentar, en términos de la batalla ideológica, el proyecto neoliberal de reestructuración del capital exige la desideologización de este lenguaje, porque, en términos de Petras, «el proceso de retirada/reconcentración [del trabajo] requiere que «deconstruyamos` o desmitifiquemos el lenguaje del análisis social» (1999:55), y, aún más, requiere la tarea de mantener la luz de la crítica social, a raíz de la teoría marxista, en la perspectiva de la totalidad y la revolución. Creo que es necesario, en el contexto actual, para el intelectual y el militante: a) volver a las categorias fundacionales del capitalismo: explotación, contradicción capital-trabajo, imperialismo, luchas de clases, plusvalía, teoría del valor-trabajo, etcétera; b) retomar la 


\section{CARLOS MONTAÑo}

perspectiva de la transformación social, de superar el orden del capital, de la revolución; c) superar las visiones fragmentadas de la realidad (positivista, sistémica o posmoderna), recuperando una perspectiva de totalidad; d) asumirse como un "intelectual orgánico», comprometido, articulado con el movimiento de la historia, con los movimientos sociales, con las clases trabajadoras organizadas, sin confundir la actividad científica o profesional con la militancia partidaria.

\section{La constitución de la ideología y los proyectos del «tercer sector»}

En este contexto de profunda ideologización, mistificación y desarticulación de la totalidad social, y de la cooptación de una «izquierda posibilista» (intelectual y militante), aparece el término «tercer sector», con un claro origen de clase y una clara función ideológica de sectorizar (fragmentar) a la sociedad en tres instancias supuestamente desarticuladas, creando una imagen ideológica de un supuesto «sector» autónomo y homogéneo, que sería «popular», «progresista», un espacio de «participación», «asociación» $\mathrm{y}$ «comprensión», sin conflicto interno o contradicción y que intervendría eficientemente en las respuestas a las necesidades sociales que el Estado está abandonando. El uso del término «tercer sector» desvía la atención de los desprevenidos a pensar en acciones sociales solidarias, desarrolladas voluntariamente, dentro del alcance de la sociedad civil..., un verdadero «canto de sirena», incluso para los oídos de aquellos que honestamente aspiran a la igualdad y la justicia social: estas son funciones desconcertantes e ideológicas (véase Montaño, 2002). El término «tercer sector», por lo tanto, 
funda una ideología y un proyecto social. Echemos un vistazo más de cerca a esto.

Actualmente, es posible identificar la disputa de al menos cuatro proyectos sociales importantes, cada uno basado en diferentes valores y principios, que conciben algún tipo de tema y que guían diferentes ideologías y acciones sociales:

1. Proyecto revolucionario, fundamentalmente de inspiración marxista, que tiene como objetivo, gradual o abruptamente, superar el orden capitalista. Lo mismo se guía por los valores destinados al desarrollo de una sociedad sin clases, fundada en la emancipación humana y organizada a través de la asociación de productores libres, basada en la erradicación del control del capital, la explotación y las formas de dominación. El sujeto revolucionario se centra en su determinación de clase, enfrentando a la clase trabajadora (que depende de la venta de su fuerza laboral para insertarse en el proceso productivo y obtener sus medios de vida) y a la clase capitalista (la burguesía, que, propietaria de los medios de producción, compra y explota la fuerza laboral). Las acciones desarrolladas en torno a este proyecto se centran en las luchas de clases (orientadas directamente a la contradicción capital-trabajo y a los fundamentos del orden burgués) y las luchas sociales complementarias (orientadas a las diversas formas particulares de expresión de la «cuestión social», formas de desigualdad y discriminación social).

2. Proyecto reformista, tanto en su aspecto liberal-keynesiano como socialdemócrata, hegemónico entre los años del segundo periodo de posguerra y la crisis capitalista contemporánea, representa el expansionismo del capitalismo productivo/comercial junto con cierto grado de desarrollo de los derechos civiles, políticos, sociales y laborales, con el objetivo de crear una fuerza laboral masiva para satisfacer las necesidades del capital, 


\section{CARLOS MONTAÑO}

promover su capacidad de consumo masivo e involucrar a la clase trabajadora en este proyecto social. Este proyecto fue articulado, particularmente en los países de América Latina, como un proceso de desarrollo industrial-nacional («desarrollismo»), fuertemente apoyado por el proteccionismo industrial y estimulando el consumo en los países. En este caso, existe un proceso de nacionalización/publicidad/nacionalización, que estimula y protege a la industria mediante la inyección de recursos públicos, pero que reconoce y responde a las demandas y necesidades de los sectores laborales. El sujeto aquí se concibe como el ciudadano, portador de derechos, y quien desarrolla sus acciones en torno de la defensa y expansión de estos derechos, dentro de la legalidad del orden capitalista; así, se trata de acciones sindicales y laborales, manifestaciones y demandas para que el Estado medie los conflictos sociales y responda a las demandas particulares de los ciudadanos.

3. Proyecto neoliberal de inspiración monetarista, bajo el mando del capital financiero, que busca, en el contexto actual de crisis, garantizar los márgenes de ganancia del capital, desmantelar los derechos laborales, políticos y sociales, históricamente conquistados por los trabajadores, acentuando la explotación de quienes viven de su trabajo y absorbiendo capitales pequeños y medianos. Dicho proyecto, ahora absolutamente hegemónico, se basa en los valores y principios de la desregulación del mercado y las relaciones laborales, en defensa de la «libre competencia», buscando la responsabilidad de los individuos, la falta de responsabilidad social del Estado y la exención del capital. Este proyecto concibe, como tema, el desglose de la ciudadanía en al menos dos tipos: el ciudadano consumidor (un «actor de libre competencia» en el mercado) y el ciudadano usuario (individuos que, en su defecto, dependen de la ayuda estatal o la caridad de individuos de 
la sociedad civil o «responsabilidad social» corporativa). Así, las acciones promovidas en este proyecto están orientadas tanto al actor en el mercado promoviendo su autoestima, su «empoderamiento», su formación, su autonomía en la búsqueda de «emprendimiento» y fuentes autónomas de ingresos, así como el desmantelamiento de la acción social estatal «paternalista»: desarrollar un proceso de privatización/desnacionalización/privatización y promover la solidaridad y la acción voluntaria de la sociedad civil y las empresas destinadas a ayudar a las personas que fracasan en el mercado. Este proyecto neoliberal ha sido camuflado en denominaciones como «tercera vía» o «neodesarrollismo», que, de hecho, no representan nada más que pequeños ajustes para mantener sus fundamentos en el nuevo contexto.

4. Proyecto de la «izquierda posibilista», fundado en la razón posmoderna subjetivista y desmovilizadora, es un pensamiento que rompe con la comprensión de la realidad por la razón, concibiendo cada experiencia subjetiva como la base del conocimiento de las microrrealidades. Esta racionalidad alberga tanto autores como perspectivas verdaderamente conservadoras (p. ej., Lyotard) y progresistas (p. ej., Boaventura de Souza Santos), en este último caso se trata de la «izquierda posibilista». La base de esta racionalidad es la inexistencia de una realidad estructural, pero de realidades concebidas a partir de la percepción subjetiva de cada individuo y, por lo tanto, la inexistencia (o falta de precedencia) de proyectos macrosociales. El pensamiento posmoderno desprecia la noción de la realidad objetiva y de macroproyectos sociales (en oposición a todas las corrientes que se originan en la modernidad), y sobrevalora la experiencia subjetiva, la percepción y el significado de cada individuo (donde la realidad objetiva es reemplazada por la experiencia subjetiva) y proyectos 


\section{CARLOS MONTAÑo}

locales y singulares (fragmentados y desarticulados de los fundamentos de la estructura social). Por lo tanto, el sujeto (en realidad, el «actor») concebido aquí son los individuos o pequeños grupos reunidos por «identidades» particulares, que, en el ámbito de la sociedad civil, o «tercer sector» (no en el Estado ni en el mercado), debe actuar, en asociación, con el objetivo de cambiar las situaciones singulares. En este caso, sus proyectos y acciones sociales están orientados a empoderar a las personas (autoayuda, empoderamiento, emprendimiento, automotivación, capacitación, etcétera) o ayudar a otros (solidaridad, responsabilidad social corporativa, asociaciones, filantropía, etcétera).

Observemos que, si los fundamentos de los proyectos neoliberales y los de la «izquierda posibilista» son esencialmente diferentes (el neoliberalismo concibe al actor en el mercado y el pensamiento posmoderno lo sitúa en la sociedad civil; el proyecto neoliberal apunta al beneficio capitalista y el proyecto de la «izquierda posibilista» tiene como objetivo cambiar las condiciones de vida de las personas), sus acciones son significativamente similares o complementarias (en ambos casos fundadas en la noción de la responsabilidad propia de los sujetos y de la falta de responsabilidad social del Estado). Así, la ideología y el proyecto del «tercer sector» están marcados por la confluencia y funcionalidad con los proyectos neoliberales y de "la izquierda posibilista». De hecho, muestra una relación articulada y funcional entre los proyectos hegemónicos del gran capital (el proyecto neoliberal) y sus operadores ideológicos y difusores (la «izquierda posibilista»).

Veamos, entonces, cómo se conforma la ideología del «tercer sector», que a su vez constituye un verdadero proyecto social. 


\section{Formación de la ideología del «tercer sector»: el canto de las sirenas}

Este término, por lo tanto, abarca una ideología, que presenta conceptos, valores, intereses, de manera mistificada y desconcertante, para constituirse como una ideología hegemónica, aceptada como algo natural y/o deseable por todos. Es un «canto de sirenas». ${ }^{4}$

Lo que llamamos, entonces, la ideología del «tercer sector» parte de la comprensión de la acción social de los individuos desarrollada dentro del ámbito de una «sociedad civil» abstracta, no sólo desarticulada de la base económica de la sociedad y de las relaciones contradictorias de producción (en una clara deseconomización de las relaciones sociales), pero también desconectada de los conflictos derivados de ellos (promoviendo una despolitización de ellos), transformando a la sociedad civil contradictoria y conflictiva en un «tercer sector» homogéneo y dócil, donde cada individuo, cada actor, desarrollaría conscientemente su acción a partir de intereses e identidades únicos. Esta ideología tiene sus raíces tanto en la tradición liberal, en las corrientes neokantianas, como en la (ir)racionalidad posmoderna. Veamos:

${ }^{4}$ La mitología griega dice que las sirenas, seres que vivían cerca del mar, en parte una mujer y en parte un pájaro (más tarde dada la forma de un pez), hijas del río Aqueloo y Terpsícore, la musa de la danza, eran dueñas de una belleza inigualable, y su canto tan dulce, hermoso y mágico, que cautivó a los marineros que las escucharon, seduciéndolos y llevándolos al naufragio y la muerte segura. La leyenda dice que sólo dos seres podían escuchar sin sucumbir a su canto. Un dios y un hombre. Primero, Orfeo, dios de la música y la poesía, logró tal hazaña cantando una música tan hermosa y atractiva que canceló la magia de la canción de las sirenas. La otra hazaña, descrita en la Odisea de Homero, cuando en su viaje de 17 años en su camino de regreso a la isla de Ítaca, después de la guerra de Troya, Ulises (u Odiseo, como el nombre griego), se enfrentó a innumerables desafíos y seres míticos, al cruzar los mares se enfrenta con la canción de las sirenas. Sin ser un dios, y consciente de su fragilidad humana, alertado por la bruja Circe, el héroe griego tapa los oídos de sus marineros, para que no escuchen el canto de las sirenas. Sin embargo, ansioso por escucharlo, pide que lo aten muy fuertemente al mástil, para escuchar su canción seductora sin ser atraído por el mar, donde ciertamente perecería. 


\section{CARLOS MONTAÑo}

La ideología del «tercer sector» toma del liberalismo el concepto formalde «libertad» cuando concibe a los sujetos como actores «libres», ya sea en la sociedad civil o en el mercado.

Además, basándose en Weber y su categoría de «acción social» (acción orientada subjetiva e intencionalmente a obtener respuestas o reacciones de otro individuo [Weber, 1969, v. I: 5]), la «acción social», considerada racional e intencionalmente orientada, es deshistorizada y sin referencia a la estructura social y la totalidad, contribuyendo así a la formación de la ideología del «tercer sector».

Influenciado por el enfoque weberiano de la «acción social» se desarrolla una «sociología de la acción», formulando una comprensión «accionalista» (Touraine, Evers, etcétera), particularmente sobre los movimientos sociales. El enfoque nacionalista subsidia la ideología del «tercer sector» porque considera la centralidad del actor en su identidad (particular, y lejos de la contradicción fundacional del sistema capitalista entre capital y trabajo) y en la dimensión cultural (desarticulada de la economía y la política).

La ideología del «tercer sector» también se nutre del trabajo de Habermas al considerar la intercomunicación, la «acción comunicativa», el poder del lenguaje, como el centro de las relaciones y acciones sociales, lo que resulta en «consensos», «entendimientos», asociaciones.

En el pensamiento posmoderno, la realidad deja de ser objetiva para convertirse en el producto subjetivo del sentido (significado) que le dan los individuos; pierde su carácter universal para volverse meramente singular, fenomenal. La ideología del «tercer sector» tiene en la razón posmoderna un pilar fundamental, sintetizando aquí la fragmentación y la sectorización de la realidad social, su separación de la totalidad, separada de las dimensiones económicas y políticas, pero relacionando lo «social», dentro del 
ámbito del «tercer sector», a la dimensión cultural y comunicativa, donde lo real sólo puede considerarse desde la experiencia y su significado para el individuo, donde es responsable de su situación de vida y de superarla.

De esta manera, entendemos por ideología del «tercer sector» el conjunto de términos y lenguajes, conceptos teóricos y valores éticos y políticos, que sustentan la autorresponsabilidad de los sujetos por sus propias condiciones de vida y por la solución de sus problemas y satisfacción de sus necesidades, desresponsabilizando al Estado y exonerando al capital en esta tarea.

Esta ideología, que trae su lenguaje «progresista», resuena como un «canto de sirenas», que canta y encanta, seduce a sectores de la izquierda, intelectuales y políticos, lanzándolos a adherirse a él, fundando la ideología del posibilismo ${ }^{5}$ y ahogando cualquier pretensión de transformación social estructural.

\section{Formación de proyectos del «tercer sector»: la trampa del caballo de Troya}

Pero este término (ideológico) esconde un proyecto. El término «tercer sector», además de su mistificación ideológica, esconde un proyecto social: el proyecto, que existe en el programa neoliberal, que articula los diversos subproyectos insertados en la ideología de la autorresponsabilidad de los

${ }^{5} \mathrm{La}$ «ideología del posibilismo», y por lo tanto la «izquierda posibilista», está respaldada por la siguiente idea: dado que la transformación social no es posible (al menos a corto y mediano plazo), invertiremos nuestras energías militantes en esas acciones y esos proyectos que se pueden realizar a corto plazo. Así, se funda una «militancia de resultados», orientada al corto plazo, a lo inmediato. Esta ideología llevó, en un choque, a incontables militantes a abandonar el proyecto revolucionario para contentarse con la «economía solidaria», la «participación local», el «empoderamiento», etcétera. 


\section{CARLOS MONTAÑo}

individuos y la desresponsabilidad del Estado, con el objetivo de exonerar al capital. ${ }^{6}$ Así, esta ideología se materializa en los Proyectos del «Tercer Sector».

Este verdadero proyecto del "tercer sector», de acuerdo con sus fundamentos de autorresponsabilidad del individuo y la falta de responsabilidad del Estado, se desarrolla en varias propuestas, también disfrazadas por los términos con que las llama, como los proyectos de «economía solidaria», «empoderamiento», «emprendimiento»y «empleabilidad», «combate al hambre y la pobreza» y «generación de empleo e ingresos», «democratización de la sociedad civil», «políticas de responsabilidad social corporativa» $\mathrm{y}$ «responsabilidad ambiental», entre otros. Cada una de estas propuestas, de estos proyectos, se basa en la responsabilidad propia de los individuos y la falta de responsabilidad del Estado, aliviando al capital. Muchos de ellos son propuestos explícitamente por el Banco Mundial (BM), el Fondo Monetario Internacional (FMI), los gobiernos neoliberales, las corporaciones capitalistas transnacionales.

Por lo tanto, este proyecto ha estado operando como un verdadero «caballo de Troya».

${ }^{6}$ La falta de responsabilidad social del Estado, la exención del capital y la responsabilidad propia de los individuos es típicamente neoliberal; en su texto Derecho, legislación y libertad Hayek afirma: «Es importante que, en el orden del mercado (erróneamente llamado «capitalismo), las personas crean que su bienestar depende, en esencia, de sus propios esfuerzos $y$ decisiones» (apud, Montaño, 2002:82).

${ }^{7}$ Los griegos declararon la guerra de Troya a los troyanos después del secuestro de Helena, esposa de Menelao, rey de Esparta. Después de nueve años de conflicto infructuoso, los griegos, que no pudieron penetrar los muros de Troya, fingen abandonar el lugar en sus barcos, regresar a sus hogares y dejar a Troya sin ser cuestionados. Al visitar la tierra que había sido ocupada por los griegos, los troyanos encontraron lo que parecía ser una ofrenda: un gran caballo de madera. Seguro de que era un reconocimiento de los enemigos y un regalo de los dioses, los troyanos llevan el caballo a la ciudad fortificada, cuyos muros no podían romper 
Hoy en día, los sectores de la intelectualidad (posibilista) de izquierda, la clase trabajadora y la población en general, son seducidos por el origen y la apariencia de estos términos (que representaban banderas históricas de luchas: «democracia», «participación», «empoderamiento», «solidaridad», etcétera), por el poder ideológico contenido en ellos, y terminan abriendo las puertas y dejando entrar, dentro de las paredes y rompiendo sus defensas, aceptando y adhiriéndose a estos proyectos, como «una ofrenda de los dioses», un «regalo griego». No se dan cuenta de que, escondidos en estos proyectos, en estos "caballos de Troya», están, indemnes y fuertes, los valores, intereses, visiones del mundo de la gran burguesía neoliberal.

Las banderas levantadas hoy en día por los defensores de la autorresponsabilidad se presentan en discursos tan de moda como: «iNo cambies el mundo, cámbiate!», «iNo cambies las cosas, cambia tu actitud!», «iNo busques empleo, busca trabajo!», «iSé emprendedor!», «[Sé tu propio jefe!», «El problema no está en la sociedad, está en tił»

Resuenan seductoramente como «cantos de sirenas», atrayendo a individuos, en masa, a abandonar sus barcos, el proyecto revolucionario, y adherirse a las alternativas de cambios subjetivos y/o singulares, y constituyen «caballos de Troya», verdaderas trampas que apuntan a generar confianza, rompiendo la resistencia de muchos de los que sinceramente anhelan una sociedad más justa.

los griegos, y celebran la victoria y el «regalo». El caballo era, de hecho, una estratagema, una trampa, para invadir la ciudad de Troya: llevaba dentro algunos soldados griegos que en plena noche abrieron las puertas de la ciudad de Troya para facilitar la entrada de todo su ejército, saqueando y conquistando la ciudad. Lo que los griegos no lograron en nueve años de guerra, con todo su arsenal militar, lo lograron mediante el engaño y la persuasión. Aquí está el truco del «caballo de Troya». 
Desarrollo comunitario, economía solidaria, empoderamiento y participación. ¿Un camino hacia la lucha social o hacia la responsabilidad de los sujetos por sus necesidades?

Tratemos aquí, a partir de lo expuesto, las propuestas de «desarrollo comunitario» y «neodesarrollismo», «economía solidaria» (o «social»), «empoderamiento» $\mathrm{y}$ «participación social».

\section{Desarrollo comunitario y neodesarrollismo}

Dependencia y desarrollo en América Latina. A partir de los años 1950 y 1960, dos grandes teorías tienden a lanzar interpretaciones diferentes (y antagónicas) sobre la condición del capitalismo en Brasil y sobre su camino hacia la industrialización y la modernización.

Bajo la influencia de la «Teoría general» de Keynes (1985), y estructurada por la Comisión Económica para América Latina y el Caribe (Cepal), creada en 1948 por el Consejo Económico y Social de las Naciones Unidas (Ecosoc), la teoría del «desarrollo». Basada en el ingreso nacional y per cápita y el ritmo de inversión, clasifica a los países como a) «desarrollados», b) «en desarrollo», y c) «subdesarrollados», como etapas de un «proceso natural» que experimentarían todos los países: el subdesarrollo como etapa inicial del necesario desarrollo económico. Para la Cepal, este proceso de desarrollo económico y social debe ser estimulado por el Estado y con la participación de la sociedad, a través de objetivos de crecimiento industrial e infraestructura, que promoverán una mayor producción y consumo, y en consecuencia un mayor bienestar social. En este caso, la transición de un país subdesarrollado a un país desarrollado sería el producto de inversiones estatales en 
producción, consumo e infraestructura (servicios productivos, comerciales y sociales). Así es como surge el «desarrollismo» en los países latinoamericanos, que en Brasil caracterizarán fundamentalmente al gobierno de Juscelino Kubitschek y el «milagro económico» de la dictadura militar.

Contrariamente a esta visión, que considera el proceso de desarrollo como un fenómeno autónomo para cada nación, la teoría de la «dependencia» surge en los 1960-1970. En ella, autores como Theotônio dos Santos (1972), Ruy Mauro Marini (1977) y André Gunder Frank (1983), basados en el trabajo de Marx e inspirados en las categorías trotskistas de «desarro1lo desigual y combinado» (Trotsky, 2007:19) y el imperialismo de Lenin (1979), piensan en el desarrollo y el subdesarrollo en el capitalismo mundial como un proceso que ocurre en la relación entre países y no de manera autónoma para cada nación.

Por lo tanto, se concibe, en el sistema capitalista mundial, la existencia de países desarrollados y subdesarrollados (y dentro de cada nación, áreas modernas y ricas, que viven con otras pobres y atrasadas), no de acuerdo con las características individuales y endógenas, sino de acuerdo con sus posiciones como países de «centro» y «periferia», en una relación estructural y sistémica: los países desarrollados lo son por su relación de «explotación» con los países periféricos. Estos últimos, considerados como dependientes o neocolonias, tienen, a su vez, su condición explicada no por el grado de desarrollo, sino por la posición subordinada, periférica (e incluso «semiperiférica») y dependiente en el sistema capitalista mundial.

La dependencia marca, más que un proceso de desarrollo de una nación individual, una relación estructural, donde este proceso puede ocurrir incluso en el país periférico por estímulo del país central (y sus corporaciones privadas), lo que lleva a una relación de dependencia centro-periferia: la 


\section{CARLOS MONTAÑo}

periferia depende del financiamiento y la tecnología de la metrópoli para desarrollarse, y esto viene en forma de préstamos, bienes, donaciones o incluso la acción de las sucursales de empresas transnacionales, mientras que el centro, sus Estados y sus corporaciones, comienzan a absorber una buena parte de las ganancias generadas en estos países recientemente industrializados. El saqueo de la riqueza de las naciones pobres por parte de los ricos ya no se debe (exclusivamente) al saqueo o usurpación de los recursos naturales; ahora las naciones imperialistas toman buena parte de la riqueza producida industrialmente en los países periféricos y semiperiféricos (dependientes, neocoloniales) por medios capitalistas: el pago de la tecnología transferida, la amortización de la deuda generada por los préstamos y la circulación de capital intraempresarial (el beneficio generado en las sucursales periféricas se transfiere a sus empresas matrices en el centro).

En esta concepción, puede haber un país atrasado, dependiente y subordinado que, sin embargo, puede tener un grado significativo de desarrollo industrial. Es el caso, en el momento, así como en el contexto actual, de Brasil, México y Argentina. Naciones cuyo importante y significativo desarrollo económico-industrial tiene lugar en su condición de países periféricos y dependientes; países que, debido a que están ubicados en la periferia del capitalismo y debido a su dependencia, presentan áreas de modernización industrial significativa, totalmente capitalistas, que viven con áreas desindustrializadas y atrasadas, con relaciones precapitalistas (neoesclavitud, latifundio, economía de subsistencia, etcétera), y tienen una gran acumulación capitalista (con una alta concentración de capital, en pocas manos) y enormes sectores regionales y de población completamente empobrecidos: en la expresión popularizada en 1974 por el economista Edmar Bacha, Brasil es un «Belíndia» (un país cuya distribución 
desigual de la riqueza combina una Bélgica pequeña y rica con una India grande y pobre), con Brasil situado actualmente entre los 10 países con el producto interno bruto (PIB) mundial más alto, es el número 70 en el índice de desarrollo humano (IDH), por lo que se encuentra entre los 12 países con la mayor desigualdad en la distribución del ingreso (con un coeficiente de Gini de 0.57).

Este aspecto es central, ya que el gran capital encontrará una fuente invaluable de ganancias en el proceso de industrialización de los países periféricos.

En esta teoría, la superación de la condición de país dependiente ya no es el resultado del desarrollo capitalista, sino que supone una ruptura con el imperialismo, e incluso con el orden capitalista: una revolución socialista.

Para relativizar este camino, a partir de la noción de «dependencia», pero contrario a este resultado, aparece primero en el trabajo de Celso Furtado (2007 y 1961) y después en el de Fernando Henrique Cardoso y Enzo Faletto (1970) una versión cepalina de dependencia: contrario a la salida socialista, aceptar la «inserción autónoma» del país en el escenario capitalista internacional y concebir un proceso de «industrialización dependiente», sin romper con los intereses del gran capital internacional y los países centrales, a través de una fuerte inversión estatal.

Sin embargo, hoy en día, la criticada (y supuestamente superada) «teoría desarrollista» vuelve a convertirse en una referencia en el análisis del país. Paradójicamente reintroducido en el gobierno de uno de los autores de la «dependencia», Fernando Henrique Cardoso, y después de él en los gobiernos de Lula y Dilma, pero con un nuevo nombre: los llamados «países en desarrollo» ahora se llaman "países emergentes», reintroduciendo el concepto evolutivo y autónomo de «desarrollismo», donde, manteniendo 


\section{CARLOS MONTAÑo}

y consolidando su condición de periferia y dependencia, se pretende un proceso de modernización conservador, como el Programa de Aceleración del Crecimiento (PAC).

\section{Expansión capitalista y desarrollismo dependiente}

En el contexto de la expansión capitalista en el segundo periodo de posguerra (1945), el mercado capitalista requiere su expansión mundial. La división mundial impide la expansión en dos bloques: el capitalista (bajo el mando hegemónico de Estados Unidos) y el socialista (unido o vinculado a la Unión Soviética). O, para decirlo de otra manera, el mercado mundial se dividió en dos bloques, claramente impenetrables entre sí, lo que obligó al capital a expandir su mercado dentro de los límites del «mundo occidental».

Así, en la fase «imperialista» del capitalismo (véase Lenin, 1979), el gran capital promueve una nueva forma de colonialismo en los países latinoamericanos: la dependencia tecnológica y financiera.

La motivación para este proceso de «desarrollo» en las antiguas colonias, en los países actuales del llamado «tercer mundo» (periférico) es la mayor acumulación de capital. Mandel aclara esto: si en el siglo XIX hasta el final de la Segunda Guerra Mundial era conveniente que el capital produjera en centros metropolitanos (países centrales); después de la depresión del 29 y la Segunda Guerra Mundial, es importante que los intereses del gran capital transfieran algunas áreas de producción a la periferia: «El patrón de las industrias de exportación imperialistas se desplazó cada vez más hacia las máquinas y los bienes de capital (...) Sin embargo, la creciente exportación de elementos de capital fijo provoca el creciente interés 
de los mayores grupos de monopolio por una incipiente industrialización del tercer mundo», lo que justifica que «este hecho (...) es la raíz básica de toda 〈ideología de desarrollo»» (Mandel, 1982:42-43, 57 y 243). Para el autor, «la superganancia sólo puede obtenerse a expensas de los países, regiones y ramas industriales menos productivas» (Mandel, 1982:70). Sin regiones, países e industrias subdesarrollados «no puede haber transferencia de excedentes a los desarrollados» (Mandel, 1982:70).

Así nació el «desarrollo industrial» en América Latina, subordinado a los intereses expansionistas del capital internacional. Los países periféricos (particularmente los latinoamericanos) ya no son meras colonias que exportan materias primas e importan productos manufacturados, y ahora comienzan a procesar bienes industriales. El gran capital internacional necesita una producción más barata y más consumo. Nuestros países pueden producir más barato (con una mano de obra más barata y una abundancia de recursos naturales) y consumir más.

Pero para eso, es necesario promover un proceso económico y social que transformará a nuestros países pobres, antiguas colonias, saqueadas de toda su riqueza durante siglos, en naciones industrializadas y consumidoras. Es necesario, para los intereses del gran capital internacional, «desarrollar» nuestros países. Es decir, desarrollar nuestros mercados, de producción y consumo, de acuerdo con los intereses hegemónicos del capital internacional. Un ejemplo de esto es el sello distintivo del gobierno de Juscelino Kubitschek: crecer «50 años en 5».

Es esta la necesidad de un gran capital — para expandir la capacidad productiva y de consumo de los países latinoamericanos, preservando una relación de dependencia y control político y económico, ahora centrado en la tecnología y el financiamiento necesarios para tal proceso- y es por 


\section{CARLOS MONTAÑO}

las presiones y luchas de gente de estos países por abandonar la situación de pobreza y miseria — luchas de clase, de pueblos indígenas, de los «miserables»- que comienza el proceso de «desarrollo» en nuestros países, conocido como «desarrollismo».

Los países «subdesarrollados», con la inyección de recursos, se convertirían en países «en desarrollo», para finalmente alcanzar la condición (ideológica) de «desarrollados». Y este proceso tiene lugar con la supervisión y el estímulo del gran capital internacional. En otras palabras, el gran capital, como parte de su proceso expansionista dentro de los límites del «mundo occidental», inyectará recursos en los países latinoamericanos para financiar su adaptación a las necesidades del mercado (producción y consumo).

Para promover este desarrollo económico, entre 1961 y 1970, se estableció el programa «Alianza para el Progreso» (Alpro) en la Organización de los Estados Americanos (OEA). Este proceso, por lo tanto, no tiene nada que ver con una supuesta ruptura o superación de la condición de dependencia o periferia en Brasil: el desarrollismo confirma y preserva la relación de dependencia y desigualdad entre los países del centro y la periferia.

\section{Crisis de capital y hegemonía neoliberal}

Es un consenso entre los intelectuales que el sistema capitalista, después de casi 30 años de clara expansión económica (1945-1973), entra en una profunda crisis: en su patrón de producción (fordista), en su sistema de regulación (keynesiano), en su Estado (bienestar social), tipo de trabajador (especializado), racionalidad (positivista), crisis fiscal, patrón del dólar, fuentes de energía (petróleo), bajo consumo. En realidad, lo que se observa hoy es una crisis general, sistémica. 
Ante tal fenómeno, la fracción de la clase hegemónica (el gran capital financiero) aliada a los capitales nacionales desarrolla una nueva forma de enfrentar la crisis, por un lado, expandiendo la explotación del trabajador y, por otro lado, sometiendo a los pequeños y medianos capitales. Así, después de un estallido de dictaduras militares, surge la nueva respuesta del capital a la crisis: el proyecto neoliberal. El programa neoliberal, por lo tanto, representa la estrategia hegemónica actual para la reestructuración general del capital (que para América Latina sigue la prescripción del Consenso de Washington de 1989) frente a la crisis y las luchas de clases, y que deriva básicamente en tres frentes articulados: el combate contra el trabajo (leyes y políticas laborales y las luchas sindicales y de izquierda), la llamada «reestructuración productiva» y la «(contra)reforma del Estado» (véase Montaño, 2002).

\section{Desarrollo en un contexto de crisis o "neodesarrollismo» preservando/actualizando la "ortodoxia neoliberal»}

Es en este contexto de crisis y hegemonía neoliberal que se restaura y reconfigura el proyecto y el debate sobre el «desarrollo».

Si en la fase de expansión capitalista y la Guerra Fría había un excedente económico suficiente para financiar políticas públicas (sociales, infraestructura, promoción de la producción y el consumo) y para promover el «desarrollo» (industrial/comercial y social) en países centrales y particularmente en los países de América Latina (dado el interés del gran capital en la producción barata y el consumo abundante en esta región), en el periodo de crisis capitalista, fin del bloque socialista y hegemonía neoliberal, este excedente disminuye drásticamente, lo que requiere una reducción 


\section{CARLOS MONTAÑO}

del gasto público social y los impuestos sobre el capital para mantener las tasas de acumulación y redirigir la inversión a los países de la antigua Unión Soviética.

Si en la fase anterior el «desarrollo» constituyó un proceso vinculado a la expansión estructural de la producción y el consumo, promoviendo estructuralmente el crecimiento industrial vinculado a un cierto desarrollo social (principalmente en los países centrales), en el periodo actual el «desarrollo» adquiere un carácter subordinado a lógica financiera (altas tasas de interés, austeridad fiscal, contención del gasto público social, desregulación del mercado, reducción del «costo del país», etcétera).

$\mathrm{Si}$, en el contexto expansionista, el desarrollo era un proyecto estructural que acompañaba la expansión industrial/comercial y las conquistas políticas y sociales de las clases trabajadoras, el proyecto actual «neodesarrollista» constituye, de hecho, una variante menos ortodoxa del proyecto neoliberal en el contexto de crisis capitalista.

Si el desarrollismo de la fase de crecimiento capitalista se sustenta en un pacto social entre el capital industrial/comercial (hegemónicamente) que involucra a la clase trabajadora industrial/urbana, en el contexto actual este pacto social es reemplazado por la hegemonía del capital financiero, excluyendo las demandas de trabajadores.

En el contexto expansivo, el desarrollo industrial/comercial es parte de la política macroeconómica, que es fundamentalmente responsabilidad estatal y empresarial, con una importante participación de los movimientos sociales; por el contrario, en la actualidad, el desarrollo pierde su carácter estructural, asumiendo una forma centrada y responsable: la llamada «iniciativa empresarial», «economía solidaria», por un lado, políticas para generar empleo e ingresos (centradas no en un proceso estructural, 
sino en la promoción de la asistencia y focalizada en las «personas necesitadas»), haciendo que el Estado no sea responsable y liberando al capital, y pasa la responsabilidad a la «sociedad civil» (transformada en «tercer sector») y a los propios individuos. La «sustentabilidad» se convierte en el criterio para esta noción de «desarrollo».

El debate contemporáneo sobre (neo)desarrollismo (o "social-desarrollismo»): menos Estado y más sociedad civil y mercado —emprendedurismo, "tercer sector», responsabilidad social, sustentabilidad. En el debate de las ciencias sociales en general, estos cambios tienen un impacto.

En el debate sobre los fundamentos de la sociedad capitalista, la contradicción y las luchas de clases pierden centralidad, y los conceptos de control social, «empoderamiento», «asociación», «solidaridad», «participación» en la «sociedad civil organizada», «economía solidaria» (o social) comienzan a ganar terreno. Promover el desarrollo ahora parece estar más relacionado no con la acción estructural del Estado, articulando el crecimiento industrial con el desarrollo social, sino haciendo que la esfera social sea autónoma. La «comunidad» parece ser reemplazada por el «tercer sector»; la política social estatal, a través de la acción social de personas, ONG y/o empresas.

El neodesarrollismo, a diferencia del que marcó el proceso de industrialización latinoamericano, en un contexto de expansión capitalista y «guerra fría», ya no se apoya en los pilares del aumento de la producción y el consumo, el crecimiento de la infraestructura, la constitución de políticas sociales, servicios públicos y derechos sociales, laborales y políticos, todos configurados en función de la presencia del Estado. El llamado «neodesarrollismo» de hoy (o «desarrollismo social»), a diferencia del anterior, radica en la ideología de la responsabilidad propia de los sujetos y la falta 


\section{CARLOS MONTAÑo}

de responsabilidad social del Estado en la intervención social, aliviando al capital. Ya no es un desarrollo promovido por la intervención del Estado, sino que el neodesarrollo, cuyo operador fundamental es el individuo con necesidades, estimulado, capacitado y «empoderado» por el Estado, por el capital y por la acción solidaria del «tercer sector», alcanzará la solución a sus problemas y necesidades.

Por lo tanto, las comparaciones de los fundamentos del neoliberalismo (desde la década de 1980 en los países centrales y la década de 1990 en América Latina), la llamada tercera vía (en la década de 1990), y el «neodesarrollismo» (promovido a su vez desde 1990 hasta los 2000, y en Brasil desde el primero, pero fundamentalmente en el segundo gobierno de Lula) (véase Gonçalves, 2012; Castelo, 2012), muestran mucho más un continuum de estas tres corrientes, y sus profundas diferencias con el «desarrollismo nacional» (o «desarrollismo clásico», de los 1950 a los 1980 en América Latina), confirmando que se trata antes que de una ruptura con el neoliberalismo, posterior a la crisis (adaptada sucesivamente en «tercera vía» y en «neodesarrollismo»), más bien con el «desarrollismo nacional», de los años de expansión capitalista.

Por lo tanto, el llamado «neodesarrollismo» (o «desarrollo social») se percibe mucho más como una continuación/adaptación del «neoliberalismo» que como un «desarrollo nacional». Los fracasos de la ortodoxia neoliberal exigieron adaptaciones constantes y cambios parciales, garantizando sus fundamentos y tratando de ocultar esta relación de continuidad con el neoliberalismo: estas adaptaciones del neoliberalismo eran conocidas como tercera vía (en los 1990, e identificadas con Tony Blair y Antony Giddens, y en Brasil con Fernando Henrique Cardoso) y ahora como «neodesarrollismo» (promovido por el Banco Mundial, por Amartya Sen, 
y en Brasil desde 2003, con los gobiernos del Partido de los Trabajadores [PT] de Lula y Dilma). Es por esta razón que Castelo (2012) y Sampaio Jr. (2012) afirman que el desarrollismo nacional y el neodesarrollismo se presentan, parafraseando a Hegel y Marx, el primero como una tragedia y el segundo como farsa.

\section{La economía solidaria o social y el mercado capitalista}

La literatura dominante sobre este tema, a partir de la fría observación del aumento del desempleo, ha «prometido» la formación de una «economía solidaria» o «social», paralela y contraria a los principios del mercado capitalista, según lo declarado por su principal formulador en Brasil, el marxista Paul Singer (1998).

Según Singer, «será necesario reforzar y multiplicar las iniciativas que surgieron dentro de la sociedad civil para que la propuesta de economía solidaria gane visibilidad y pueda atraer el apoyo de las fuerzas que se oponen a la exclusión social» (1998:135). Esto permitiría, con la formación de «un nuevo sector económico, formado por pequeñas empresas y autónomos, compuesto por exdesempleados, que tenga un mercado protegido de la competencia externa por sus productos», para lograr una «solución no capitalista al desempleo» (1998:122).

¿Resulta sumamente interesante reflexionar sobre cómo, en la formación de «un nuevo sector económico», podemos lograr, en una sociedad controlada por el capital, una «solución no capitalista»? Del mismo modo, ¿cómo crear para este nuevo sector de «economía solidaria» un «mercado protegido de la competencia externa»? ¿Sería tal vez mediante mecanismos 


\section{CARLOS MONTAÑo}

extraeconómicos basados en la intervención del Estado? Si es así (como lo hizo el keynesianismo de alguna manera), en primer lugar, esto requeriría no sólo la iniciativa de una supuesta «sociedad civil» solidaria, sino también una fuerte intervención estatal, promovida por las luchas de clases y garantizada por las leyes. En segundo lugar, la hegemonía del capital permitirá la creación de un mercado tan protegido para este «sector» sólo en un segmento que no le interese (de bajas ganancias) (véase Montaño, 1999a:95 y 36 y ss.), constituyendo este proceso mucho más una estrategia de supervivencia que el desarrollo de una experiencia no capitalista (Montaño, 1999a:89 y ss.).

Según sus formuladores y defensores, la promoción de experiencias de «economía social» serviría, además de una alternativa al desempleo, como una «contratendencia al mercado capitalista», una solución «no capitalista» a un problema capitalista, una solución de la «sociedad civil» a un problema del mercado y de la producción.

Tanto De Masi como Rifkin parten de la observación de «una transformación fundamental en la naturaleza del trabajo» (véase Rifkin, 1997:13), lo que, para ellos, significaría el fin de la «sociedad industrial» y la transición al «posindustrialismo». Según Rifkin, «durante mucho tiempo, se pensó que aquellos que perdieron empleos en el sector manufacturero podrían ser re-entrenados en el sector de servicios», sin embargo, dice, hoy «éste ya no es el caso» (1997:15). Para estos autores, la tecnología parece ser el gran villano, el culpable del desempleo, la zorra a la que le damos la espalda o nos enfrentamos y sucumbimos a su hechizo. Al darse cuenta del «fin de los trabajos», lo traducen como el «fin del trabajo» y el aumento del «tiempo libre».

Por lo tanto, para De Masi, «siempre que la innovación tecnológica y estructural permite transferir el esfuerzo humano a las máquinas, surgen 
dos análisis diferentes: al principio, el fenómeno se percibe como desempleo y como una amenaza para el equilibrio social; [y] sólo por segunda vez se percibe como liberación de la esclavitud del trabajo, el hambre y la tradición» (1999a:8). Para él, los «nuevos desempleados» son, de hecho, «liberados de la esclavitud del trabajo» (sic) (De Masi, 1999:12).

Por su parte, para Rifkin el desempleo masivo es un hecho inalterable. Así, con la automatización y la carrera tecnológica cada vez más acelerada, Rifkin proyecta que para el año 2020 sólo «2\% de la fuerza laboral de este planeta estará en las industrias» (1997:14), donde 20\% de la fuerza laboral se desempeñará como trabajador del conocimiento, mientras que $80 \%$ restante será excluido de los sectores tradicionales sometidos a la automatización. Es aquí donde, con base en estos pronósticos apocalípticos, surgen las propuestas para la promoción de la «economía solidaria o social» y el «emprendedurismo».

En primer lugar, culpar al progreso técnico por el desempleo, ya que ahorra trabajo, nos lleva a un impasse ideológico, obligándonos a elegir entre una sociedad con pleno empleo pero atrasada, o una sociedad moderna, pero saturada de desempleados. De hecho, el desarrollo tecnológico, en el contexto del capital, no genera más «tiempo libre» sino, como señaló Marx, una reducción del tiempo socialmente necesario para la producción de mercancías. Marx (1980) trata, en el capítulo XXIII de El capital, la «ley general de acumulación capitalista». Particularmente en su segundo ítem, «Disminución relativa de la parte variable del capital a medida que progresa la acumulación y, con ella, la concentración», afirma: «Dadas las bases generales del sistema capitalista, llega (...) a un punto donde el desarrollo de la productividad del trabajo social se convierte en la palanca más poderosa de acumulación» (Marx, 1980:722-723). Por lo tanto, un factor constitutivo 


\section{CARLOS MONTAÑO}

de la acumulación es el desarrollo de métodos para aumentar la productividad, que al mismo tiempo son métodos para aumentar la producción de valor agregado. Y continúa: «Con la acumulación de capital, se desarrolla el modo de producción específicamente capitalista y con (...) [esto desarrolla] la acumulación de capital (...) Estos dos factores [los impulsos mutuos entre la acumulación y la forma capitalista de producir] modifican la composición técnica del capital y, por lo tanto, la parte variable se vuelve cada vez más pequeña en relación con la constante» (Marx, 1980:726).

Este hecho podría «liberar» el tiempo del trabajador si el desarrollo tecnológico y la consiguiente reducción del tiempo necesario estuvieran acompañados por un crecimiento económico y una reducción proporcional en la jornada laboral, de modo que todos trabajen menos. Esto, por supuesto, se refiere a un orden social distinto del capitalista. En el capitalismo, la apropiación privada de la tecnología, hoy un poderoso mecanismo productivo (véase Braverman, 1987; Mandel, 1982), que forma parte de los medios de producción, permite al capital controlar sus beneficios. Como resultado, en lugar de «liberar» tiempo para los trabajadores, el resultado es despidos masivos, expulsión de la fuerza laboral del mercado de producción formal.

Lo que sucede, como señala Marx, es que, con el aumento del capital global, su parte variable crece en proporciones cada vez más pequeñas —es decir, disminuye en términos relativos-, produciendo, por un lado, una población activa relativamente superflua, el Ejército Industrial de Reserva (EIR) y, por otro lado, más trabajo se concentró en unos pocos trabajadores (altamente calificados). Por lo tanto, afirma, «el aumento en el capital variable [un producto del aumento en el capital global] es entonces un índice de más trabajo, pero no más trabajadores empleados» (Marx, 1980:737). Es eso, según el mismo autor, 
el trabajo excesivo de la parte empleada de la clase trabajadora engrosa las filas de su ejército de reserva, mientras que, a la inversa, la fuerte presión que esto [el EIR] ejerce sobre eso [la masa empleada], a través de la competencia, lo obliga a trabajar demasiado y a someterse a las demandas del capital. La condena de una parte de la clase trabajadora a la ociosidad forzada [hoy llamada «tiempo libre»], debido al trabajo excesivo de la otra parte, se convierte en una fuente de enriquecimiento individual para los capitalistas (Marx, 1980:738).

Ahora, el proyecto y las propuestas de «economía solidaria» y de «empoderamiento», de hecho, buscan la autorresponsabilidad del individuo por su condición y por la solución de sus necesidades; en cuanto a Hayek, el fracaso de las personas en el mercado no es más que el resultado de la libre competencia entre sujetos con diferentes capacidades, y no tendría nada que ver con un sistema injusto o desigual, por el contrario sería el resultado natural de un sistema que garantiza libertades individuales. En este pensador neoliberal, no es la desigualdad del sistema, sino la diferencia de los individuos, lo que conduce al éxito de algunos y al fracaso de otros.

La salida al desempleo pasaría al abandonar la búsqueda de un empleo, no invertir (y luchar) en torno a la relación capital/trabajo, relación empleado/empleador, para invertir en «autoempleo», en trabajo autónomo, en microempresa o incluso en la llamada producción «solidaria». Estas soluciones individuales aparecen en el estímulo y la promoción de la llamada «iniciativa empresarial» y en los proyectos de la llamada «economía solidaria» (o «social»).

El emprendedurismo como el camino que, al mejorar las capacidades individuales, conduciría a todos en el mismo proceso: todos serían «emprendedores», ya no capitalistas y trabajadores, por lo tanto, sólo se diferenciarían 


\section{CARLOS MONTAÑo}

por sus capacidades individuales y por las etapas de desarrollo en sus empresas. No hay más contradicción entre clases, sino diferencias entre individuos, entre «empresarios».

Finalmente, la llamada «economía solidaria», dentro de las políticas anteriores, sugiere un proceso que consistiría en un camino de autoproducción basado en los lazos internos de solidaridad y cooperación, induciéndolo ideológicamente a concebirlo como una alternativa a la producción capitalista. El poder seductor de este «canto» es tan grande que permitiría poner fin a la relación salarial entre el capital y el trabajo, eliminando la explotación y, además, constituyendo una forma de superar el orden capitalista. La función principal de este proceso está oculta en esta melodía: generar una mano de obra barata, hiperexplotada y en una relación desregulada de subcontratación con el capital, estableciendo una forma de «salarios por pieza», y, aún así, pulverizando a la clase trabajadora y llevándola a abandonar las luchas de clases contra el capital.

\section{El empoderamiento del individuo y el desempoderamiento de la clase}

El poder, en su dimensión social, no natural, puede concebirse principalmente de dos maneras fundamentales: como poder sobre los otros o como poder sobre sí es decir, como dominación o como potencia. ${ }^{8}$

La primera forma de poder se refiere a una relación social, una relación hombre-hombre. La segunda forma trata con el individuo (o grupo) consigo mismo, en una relación hombre-necesidades.

${ }^{8}$ Erich Fromm afirma que «la palabra poder tiene un doble significado. El primero de ellos se refiere a la posesión del poder sobre alguien, la capacidad de dominarlo; el otro significado se refiere al poder de hacer algo, de ser poderoso» (1980:186). 
El poder como «relación social» es poder político. El poder «sobre sí»se llamará poder subjetivo o autopoder.

Por lo tanto, el poder político, en las diversas y controvertidas perspectivas del pensamiento político, económico, sociológico y filosófico, se ha asociado con la capacidad de toma de decisiones, la correlación de las fuerzas sociales, la hegemonía o la dominación. Por lo tanto, el poder político siempre se ha conceptualizado como una desigual relación social o correlación de fuerzas.

Sin pretender entrar en la concepción general del poder en cada uno de los autores, simplemente destacando el tema del «poder político» como una «relación social», veamos algunos ejemplos de esto:

Maquiavelo (1996), al comenzar la «ciencia política» en el estudio sistemático del poder, dio lecciones sobre cómo el príncipe (y el Estado) pueden ejercer su poder sobre sus súbditos, imponiendo «miedo» y/o «amor» (pp. 97-100): los sujetos aceptarán su poder en la medida en que teman y/o amen a su soberano. El poder, como una relación de dominación/subordinación, puede ejercerse tanto por el miedo (dominación) como por el amor al príncipe (aceptación). Para el autor, el poder se refiere a la relación del príncipe (el Estado) con sus súbditos.

A su vez, Karl Marx (Marx y Engels, 2010), al abordar los fundamentos del capitalismo, se centra en la relación contradictoria entre las clases fundamentales: capital y trabajo. Tal relación expresa el poder desigual de cada clase, fundando las luchas de clase. Sin embargo, Marx no concibe el «poder» como una categoría abstracta, o como un concepto universal, sino que trata el poder como una particularidad del modo de producción capitalista (MPC), es decir, como una relación entre clases sociales, que implica explotación, dominación e ideología, como aspectos constitutivos de 


\section{CARLOS MONTAÑo}

las relaciones de poder entre clases. Para Marx, el poder no sólo implica una dimensión económica (explotación), sino también política (opresión) y cultural (alienación, ideología).

El fundamento de la relación desigual de poder económico en el MPC, entre las clases, radica, para Marx, en la separación de la fuerza de trabajo de los medios de producción, cada uno de los cuales pertenece a una clase. Su reunión, en el proceso productivo, ocurre a través de la venta de la fuerza de trabajo al capital, lo que constituye una relación salarial, que basa la producción (por el trabajador) y la explotación (por el capitalista) de la plusvalía (Marx, 1980). Esta desigual relación de explotación determina, por un lado, la apropiación privada de la riqueza, la acumulación capitalista, el primer fundamento para el dominio de la clase burguesa, ${ }^{9} \mathrm{y}$, por otro lado, el empobrecimiento absoluto y relativo del trabajador.

También implica un desigual poder político: principalmente por la «subsunción real del trabajo al capital» (Marx, 1969) donde el proceso productivo en sí mismo está cada vez más controlado por el capital, fundando la alienación del trabajador del control de la producción de valores, transformándolo en una mera extensión de la máquina; segundo, por el control hegemónico del Estado (instrumentalizado para la dominación de clase) por el capital, desde donde promueve la opresión de clase (Marx y Engels, 2010). Aun así, la relación de poder entre las clases también implica una dimensión cultural, a través de la formación de una ideología que transforma las ideas y valores dominantes (de la clase dominante) en ideas y valores socialmente aceptados. ${ }^{10}$

${ }^{9}$ En los términos de Marx y Engels: «La condición esencial para la existencia y supremacía de la clase burguesa es la acumulación de riqueza en manos de particulares» (2010:51).

${ }^{10}$ Según Marx y Engels, en La ideología alemana: «Las ideas (Gedanken) de la clase dominante son, en cada época, las ideas dominantes, es decir, la clase que es la fuerza material dominante es, al mismo tiempo, su fuerza espiritual dominante. La clase que tiene a su disposición los 
En esta tradición teórica y política, Antonio Gramsci, observando la «socialización de la política» en el siglo XX, expande la noción de poder, aún como una correlación de fuerzas fundadas en las relaciones de producción entre clases, pero no sólo como una relación unidireccional de dominación y coerción (en la esfera de la «sociedad política»), sino también desarrollando una relación de dirección, de hegemonía, de consenso (en el ámbito de la «sociedad civil»), donde la relación desigual de poder implica un cierto intercambio entre las partes, el resultado de una correlación de fuerzas (véase Gramsci, 2000:254 y ss.).

Una referencia en el pensamiento político moderno, Max Weber (2012; 2012a), caracteriza el poder como «toda probabilidad de imponer la voluntad de uno en una relación social» (Weber, 2012:33); mientras que «dominación, en el sentido muy general del poder», se conceptualiza como «la posibilidad de imponer la propia voluntad sobre el comportamiento de los demás» (Weber, 2012a:188 y 191), o la «probabilidad de encontrar obediencia a un orden de cierto contenido» (Weber, 2012:33). A su vez, la dominación, cuando se refiere a un «poder legítimo», presupone un cierto grado de aceptación de los «dominados»; dicha legitimación puede ser de tipo «legal», «tradicional» o «carismático» (Weber, 2012a:193 y ss.). El poder y la

medios materiales de producción, tiene al mismo tiempo los medios de producción espiritual, lo que la somete, al mismo tiempo y en promedio, a las ideas de quienes carecen de los medios de producción espiritual. Las ideas dominantes no son más que la expresión ideal de las relaciones materiales dominantes concebidas como ideas; por lo tanto, la expresión de las relaciones que hacen de una clase la clase dominante; por lo tanto, las ideas de su dominación. Los individuos que constituyen la clase dominante tienen, entre otras cosas, también conciencia y, por esta razón, piensan; en la medida en que dominan como clase y determinan el alcance completo de una época histórica es evidente que lo hacen en toda su extensión y, en consecuencia, entre otras cosas, también dominan como pensadores, como productores de ideas, que regulan la producción y distribución de ideas de su tiempo y que sus ideas son, por lo tanto, las ideas dominantes de la época» (1993:72). 


\section{CARLOS MONTAÑo}

dominación, por lo tanto, para este autor, siempre se refieren a una relación social.

Otro ejemplo muy diferente, en la llamada «Teoría de juegos» (que proviene de las matemáticas aplicadas, pero luego incorporada por las teorías económicas, políticas y militares), un juego de "suma cero», expresa claramente una relación de poder, donde la ganancia de un jugador necesariamente representa, y en la misma proporción, la pérdida para el otro jugador (véase Fiani, 2006).

Hannah Arendt, claramente influenciada por el terror del Holocausto nazi, diferencia la fuerza del poder. Para ella, «mientras que la fuerza es la cualidad natural de un individuo aislado, el poder llega a existir entre los hombres cuando actúan juntos y desaparece en el momento en que se dispersan» (2009:212). El primero, cuando lo ejerce un individuo sobre las masas, expresa dominación. El segundo, el poder, ejercido a través de la acción, donde «los hombres actúan y hablan juntos» (Arendt, 2009:214), es una expresión de la «condición humana de la pluralidad». Para la autora, «el único factor material indispensable para la generación de poder es la convivencia entre los hombres» (Arendt, 2009:213), que muestra claramente la concepción del poder como una relación social. Por lo tanto, al diferenciar la fuerza del poder, Arendt distingue la acción aislada de la acción cobarde, en la medida en que, como señala: «Lo que mantiene a las personas juntas después de que pasa el momento fugaz de la acción (...) y lo que, a su vez, mantienen vivos al permanecer unidos, es el poder», sin embargo, «todos los que (...) se aíslan y no participan en esta convivencia, renuncian al poder y se vuelven impotentes, por muy grande que sea su fuerza y por válidas que sean sus razones» (Arendt, 2009:213).

De otra manera, Michel Foucault hace una inflexión en su discusión sobre el poder. A diferencia de la concepción institucionalista-estatista 
del poder — como dominación, como poder de negación, tal como se concibió en el tratamiento de la prisión, el hospicio, el hospital—, en su «Microfísica del poder» (Foucault, 1985) trata de un poder que no nace del Estado ni está necesariamente orientado hacia él; un poder local periférico, existente en toda la capilaridad social. Aquí, distanciándose de lo que él llama la «concepción legal o liberal» y la «concepción marxista» (o, como él reconoce, «cierta concepción actual [¿vulgar?] que pasa por ser la concepción marxista») (Foucault, 1985:174), visto como puntos de vista economicistas, Foucault desarrolla la idea de un poder que existe en todos los microespacios, lugares. Si esta concepción abre el camino para pensar en un «poder» que emana de microespacios y pequeños grupos, un «poder local», sin cambiar la correlación de las fuerzas macrosociales —lo que sin duda apoya el debate sobre el «empoderamiento»—, todavía no parece haber en Foucault una concepción completamente subjetivista del poder, de un poder sólo «sobre sí mismo», eso no representa una relación social entre diferentes fuerzas sociales, por locales, micro o singulares que puedan ser.

Finalmente, sin perjuicio del hecho de que estas son concepciones realmente diversas y diferentes, y porque no son antagónicas, el poder político siempre se concibe como una relación social, macro o micro, consensual o no. Veamos ahora la noción de poder subjetivo.

Sin embargo, el poder subjetivo, como autopoder o "poder sobre sí», trata con un poder personal, interno y psicológico, considerando al individuo fuera (o independiente) de las relaciones sociales: el individuo (o grupo) consigo mismo. Un «poder» que no se refiere a la relación hombre-hombre (poder político), sino a la relación hombre-necesidad, a la relación de cada individuo (o grupo) con sus necesidades directas. Dónde 


\section{CARLOS MONTAÑo}

llegar a ellos no dependería de las correlaciones de las fuerzas sociales, sino sólo y simplemente del potencial o la capacidad de cada uno.

Aquí es donde se inserta el llamado «empoderamiento». En la misma línea que «autoayuda», «motivación», «autoestima», «emprendedurismo», «desarrollo subjetivo», «autoempleo», el llamado «empoderamiento» está orientado a mejorar subjetivamente al individuo (o grupo) sin ninguna posibilidad de cambiar la correlación de fuerzas, ni locales ni sistémicas. En términos de Arendt, es el desarrollo de la «fuerza» individual, pero no del «poder».

Así, el concepto ideológico (y los proyectos vinculados a él) de «empoderamiento», se refieren a esta segunda forma de «poder» (subjetivo). En otras palabras, no trata con el poder político, no trata con la correlación de fuerzas, sino con el poder subjetivo, psicológico, sobre sí mismo, con la fuerza individual. Así concebido del poder, el concepto no alcanza (ni pretende alcanzar) las relaciones de dominación, opresión y subordinación y explotación. Aquí, el poder y el «empoderamiento» se refieren a procesos de «conciencia», «motivación», «autocontrol», «crecimiento personal», en una lógica de autorresponsabilidad del individuo (o grupo) para la solución de sus necesidades o carencias. Más que «poder» es «potencial»o «potenciación» individual.

Es un proceso de crecimiento subjetivo personal (o grupal) que no altera los fundamentos del poder ni la correlación de fuerzas. Muy en sintonía con discursos como: «no cambies el mundo, cámbiate a ti mismo». Veamos:

La calificación de un grupo de desempleados puede permitir que estas personas tengan mejores condiciones de acceso al mercado laboral; sin embargo, no creará nuevos empleos, siendo su éxito el fracaso de otros trabajadores. No crea nuevos empleos ni cambia el control del capital sobre el mercado laboral. O incluso, calificarlos para actividades productivas autónomas, antes de que constituya un aumento en el poder de la clase 
trabajadora, proporciona fuerza de trabajo precarizada para el capital, en una relación de subcontratación. Otra cosa sería, por ejemplo, a través de las luchas de clase, lograr una reducción en la jornada laboral que requiera un aumento en la contratación.

Por otro lado, organizar una comunidad para construir cisternas, o hacerlas responsables de su mantenimiento, puede permitir efectivamente «resolver» el problema de la falta de agua, sin embargo, confirmará y consolidará el vaciado de un derecho humano esencial para garantizar el acceso al agua, promoviendo la resignación sobre la falta de responsabilidad del Estado para garantizar este derecho. La organización es diferente para luchar por la garantía de acceso al agua como un derecho humano fundamental garantizado por el Estado.

Por supuesto, para aquellos que no tienen una fuente de ingresos, o para aquellos que no tienen acceso al agua potable, son importantes las acciones que les brinden ingresos o dicho acceso, incluso de forma paliativa, precaria y transitoria. El problema es «vender» este proceso como «empoderamiento», como un aumento en el poder de los pobres, de los subordinados, de los de «abajo», como si eso significara un camino hacia «un mundo mejor», cuando en realidad la consolidación de la subordinación confirma la dominación y expande la hegemonía y la acumulación de capital, bajo el mando neoliberal.

Aquí hay una ideología que nos lleva a apostar/creer en un llamado «empoderamiento» (como empoderamiento subjetivo, individual o grupal), abandonando las luchas que apuntan a tensar la correlación de las fuerzas sociales y los fundamentos del poder económico, político y cultural. En este «empoderamiento», la ideología de la responsabilidad del individuo se basa en la verdad. 


\section{CARLOS MONTAÑo}

Por lo tanto, si la máxima de la acción política es «dividir y reinar», las propuestas para «empoderar al individuo» (o grupo), en la medida en que separan a los individuos y grupos (eliminando la unidad de clase), y segmentan los problemas a abordar para cada uno (eliminando los fundamentos de la contradicción de clase), al final, termina desempoderando a la clase: el «empoderamiento» de individuos/grupos, cuando desagrega a la clase trabajadora y no cambia la correlación de fuerzas con su antagonista, el capital, de hecho, promueve un "desempoderamiento» de la clase trabajadora y los sectores subalternos.

\section{Participación/movilización en las luchas de clase}

y participación/movilización en la gestión de problemas locales

La participación entendida como «tomar partido» y como una militancia o acciones en el proceso de luchas en torno a los problemas que enfrentan los sujetos (clases y fracciones de clases), no es lo mismo, basado en intereses contradictorios y que, aunque pueda estar orientado a manifestaciones particulares de la «cuestión social», tiene como horizonte los fundamentos de la desigualdad en la estructura y dinámica de la sociedad capitalista, que esa participación considerada como la acción social desarrollada sólo dentro del ámbito de una sociedad civil aislada de la esfera económica, de la macro política y de los fundamentos sistémicos de la «cuestión social», desarticulados de la contradicción capital-trabajo y los antagonismos de clase, y que se desarrolla alrededor de «microespacios» (aislados) y «problemas singulares» (aislados), como las formas de participación contenida en la «microfísica del poder» de Foucault, en el llamado «poder local», en el asociativismo tocquevilleano, en las llamadas «acciones afirmativas», en 
la intercomunicación en el «mundo de vida» habermasiano, en el «empoderamiento», en la solidaridad del «tercer sector».

El primer caso trata de la «participación», las acciones que constituyen luchas de clase o luchas sociales complementarias que, directamente vinculadas a las demandas en torno a la emancipación política, tienen la emancipación humana y política como su horizonte. En el segundo caso, el término «participación» se utiliza para dar cuenta de acciones de responsabilidad propia, desarticuladas, de sujetos aislados que tienen como objetivo conquistar deseos y resolver problemas, de manera controlada, institucionalizada y/o funcional con mantenimiento del orden, el statu quo y la falta de responsabilidad del Estado y la exención del capital, que incluso significando un retroceso en la emancipación política (pérdida de derechos, garantías, respuestas estatales ya logradas). En el primer caso, el término «participación» se utiliza para complementar las luchas de clase; en el segundo caso se usa como sustituto de esos.

En este último caso, la opción de participación o movilización social, sin dirección, sin un horizonte a largo plazo (opción de activistas del «tercer sector»), tiene al menos dos consecuencias: a) crear la sensación (falsa) de que con acciones singulares se resolverían problemas específicos y/o educarían a las personas en la participación social, creando una «experiencia participativa» pedagógica y acumulativa; $y$, derivado de esto, b) cambiar las expectativas de una acción transformadora de largo alcance (de luchas de clases) a acciones inmediatas que, al poder generar pequeños cambios locales, confirmarían y reforzarían las estructuras y el statu quo.

Entonces, una cosa es la participación (o movilización) como luchas sociales, por los derechos sociales. En este caso, dicha participación o movilización se concibe, no como participación en la gestión de recursos y en 


\section{CARLOS MONTAÑo}

la ejecución de servicios sociales, sino como luchas sociales, guiadas fundamentalmente (aunque no exclusivamente) por contradicciones de clase. Tal perspectiva ya no concibe la movilización como «el resultado de la acción del gobierno», sino como un verdadero desencadenante de la acción del gobierno, como un proceso de luchas sociales que presionan y obligan al Estado y al capital a absorber ciertas demandas e incorporarlas como una función de Estado. Si en la concepción de la movilización social contenida en el debate del «tercer sector» este es el resultado de una intervención estatal que descentraliza, privatiza, externaliza o transfiere la responsabilidad de la gestión social a la comunidad, nuestra perspectiva concibe la movilización social como el proceso que conduce el Estado (y el capital) para desarrollar acciones que no fueron incorporadas en sus funciones.

Por lo tanto, las luchas desatadas en la sociedad civil no deben desarro1larse, buscando reemplazar o compensar, lo que el Estado en el contexto neoliberal está abandonando. Más bien, deben ser luchas, en primera instancia, también para preservar y expandir las conquistas históricas de los trabajadores, garantizadas dentro del Estado. A su vez, deben ser luchas que, en la sociedad civil y en la vida cotidiana, tengan como objetivo la totalidad social, como el desarrollo desde y dentro de proyectos sociales más amplios y más o menos claros que, sin agotarse en los problemas de clase, están fundamentalmente orientados por las contradicciones entre capital y trabajo. ${ }^{11}$ En tercer lugar, las luchas en la sociedad civil deben tener como

${ }^{11}$ Como lo manifiesta Lojkine, al criticar el enfoque de Castells sobre los movimientos sociales urbanos, éstos no deben reducirse al alcance de la «reproducción de la fuerza laboral», desmantelando lo económico (reproducción de medios y relaciones de producción) de lo social (reproducción de mano de obra: equipamiento colectivo y medios de consumo, servicios sociales, vivienda, etcétera). A su vez, ahora contra el enfoque de Touraine, estos movimientos sociales no pueden verse en una relación de clara externalidad con el poder del Estado, como 
horizonte la articulación de las otras esferas de la sociedad; articulando así los proyectos corporativos en lucha, tanto en el Estado, en el mercado, en el ámbito de la producción, en la sociedad civil, en la vida cotidiana. No es posible confiar mucho en las luchas sociales que, operadas en la sociedad civil, dejan de lado otras esferas sociales (como el Estado y el mercado), permitiendo su control por las élites.

Otra cosa es la participación (o movilización) mediante el manejo controlado de los recursos de la comunidad. Esta lógica reproduce la concepción de la política social y los servicios sociales y de asistencia como resultado de la concesión del Estado, y se basa en el sistema de solidaridad individual, ayuda mutua y autoayuda. El Estado descentraliza, transfiere recursos (a través de asociaciones) al sector privado, facilita legalmente la actividad de las «organizaciones de la sociedad civil de interés público», y éstas «se movilizan» actuando en la gerencia o gestión (controlada) de respuestas a necesidades sociales específicas y situadas. Aquí, la movilización de la población es tanto en asociación con el Estado, con una dirección clara de la política gubernamental, como una movilización como resultado de la acción del gobierno; descentraliza, transfiere dinero público, define la organización «social» para llevar a cabo la acción social, y sólo entonces la comunidad se moviliza y participa en acciones ya establecidas por el poder instituido. Nada, aparte de la provisión de servicios (generalmente precarios) y una cierta experiencia participativa, se puede esperar de este tipo de movilización mediante la gestión controlada de recursos.

políticamente puro ( $c f r$. Lojkine, 1981:300-301). Estos movimientos sociales deben entenderse en la articulación de las esferas económica, política y social, y en los espacios superpuestos del Estado, el mercado y la sociedad civil. 


\section{CARLOS MONTAÑo}

\section{Referencias}

Arendt, Hannah (2009), A condição humana, Rio de Janeiro, Forense Universitária. Braverman, Harry (1987), Trabalho e capital monopolista. A degradação do trabalho no século XX, Rio de Janeiro, Guanabara.

Cardoso, Fernando Henrique y Enzo Faletto (1970), Dependência e Desenvolvimento na América Latina, Rio de Janeiro, Zahar Editores.

Castelo, Rodrigo (2012), «O novo desenvolvimentismo e a decadência ideológica do pensamento econômico brasileiro», Serviço Social \& Sociedade (112).

Coutinho, Carlos Nelson (1994), Marxismo e politica. A dualidade de poderes e outros ensaios, São Paulo, Cortez.

De Masi, Domenico (1999), Desenvolvimento sem trabalho, São Paulo, Esfera. (24 de marzo de 1999a), «Por mais horas de folga», Revista Exame.

Dos Santos, Theotonio (1972), Dependencia y cambio social, Santiago de Chile, CESO. Fiani, Ronaldo (2006), Teoria dos Jogos, São Paulo, Campus.

Fromm, Erich (1980), El miedo a la libertad, Barcelona-Buenos Aires, Paidós.

Furtado, Celso (1961), Desenvolvimento e subdesenvolvimento, Rio de Janeiro, Fundo de Cultura. (2007), Formação econômica do Brasil, São Paulo, Companhia das Letras.

Gonçalves, Reinaldo (2012), «Novo desenvolvimentismo e liberalismo enraizado», Serviço Social \& Sociedade (112).

Gramsci, Antonio (2000), Cadernos do Cárcere (volumen 3), Rio de Janeiro, Civilização Brasileira.

Gunder Frank, André (1983), Reflexões sobre a crise econômica mundial, São Paulo, Zahar.

Harvey, David (1993), A condição pós-moderna. Uma pesquisa sobre as origens da mudança cultural, São Paulo, Loyola. 
Jameson, Fredric (1996), Pós-modernismo. A lógica cultural do capitalismo tardio, São Paulo, Ática.

Keynes, John M. (1985), A Teoria Geral do Emprego, do Juro e da Moeda [e] Inflação e Deflação, São Paulo, Nova Cultura.

Lenin, Vladimir Ilich (1979), O Imperialismo: fase superior do capitalismo, São Paulo, Global.

Lojkine, Jean (1981), O Estado capitalista e a questão urbana, São Paulo, Martins Fontes.

Lukács, Georg (1963), La Theórie Du Roman, Genebra, Gonthier. (1974), História e consciência de classe. Estudos de dialética marxista, Lisboa, Publicações Escorpião. (1992), «Sociologia», en José Paulo Netto (org.), Grandes Cientistas Sociais, São Paulo, Ática.

Mandel, Ernest (1982), O Capitalismo Tardio, São Paulo, Abril Cultural.

Maquiavel, Nicolau (1996), O Príncipe, São Paulo, Nova Cultural.

Marini, Ruy Mauro (1977), Dialéctica de la dependencia, Era, México.

Marx, Karl (1980), O Capital. Crítica da Economia Politica, Rio de Janeiro, Civilização Brasileira.

(1969), Capítulo VI. Inédito de O capital. Resultados do processo de produção imediata, São Paulo, Moraes.

Marx, Karl y Friedrich Engels (1993), A Ideologia Alemã, São Paulo, Hucitec.

__ (2010), Manifesto Comunista, São Paulo, Boitempo. (1977), A Ideologia Alemã (Feuerbach), São Paulo, Grijalbo.

Montaño, Carlos (2002), Terceiro setor e questão social. Crítica ao padrão emergente de intervenção social, São Paulo, Cortez. (org.) (2014), O canto da sereia. Crítica à ideologia e aos projetos do terceiro setor, São Paulo, Cortez. 


\section{CARLOS MONTAÑO}

(1999a), «Microempresa na era da globalização», Questões da nossa época (69).

Petras, James (1999), Neoliberalismo: América Latina, Estados Unidos e Europa, Blumenau, FURB.

(2000), Globaloney. El lenguaje imperial, los intelectuales y la izquierda, Buenos Aires, Antídoto.

Rifkin, Jeremy (1997), «Identidade e natureza do Terceiro Setor», en Evelyn Berg Ioschpe (coord.), $3^{\circ}$ Setor. Desenvolvimento social sustentado, Rio de Janeiro, GIFE/Paz e Terra.

Sampaio Jr., Plínio de Arruda (2012), «Desenvolvimentismo e neodesenvolvimentismo: tragédia e farsa», Serviço Social \& Sociedade (112).

Singer, Paul (1998), Globalização e desemprego. Diagnóstico e alternativas, São Paulo, Contexo.

Trotsky, Leon (2007), A história da Revolução Russa, São Paulo, Sundermann.

Weber, Max (1969), Economía y Sociedad, México, Fondo de Cultura Económica. (2012) Economia e Sociedade. Fundamentos da Sociologia Compreensiva (volumen 1), São Paulo, UnB.

(2012a) Economia e Sociedade. Fundamentos da Sociologia Compreensiva (volumen 2), São Paulo, UnB. 